\title{
Association of maternal characteristics with latino youth health insurance disparities in the United States: a generalized structural equation modeling approach
}

Cinthya K. Alberto ${ }^{1 *} \mathbb{D}$, Jessie Kemmick Pintor ${ }^{2}$, Brent Langellier ${ }^{2}$, Loni Philip Tabb ${ }^{3}$, Ana P. Martínez-Donate ${ }^{4}$ and Jim P. Stimpson ${ }^{2}$

\begin{abstract}
Background: Disparities in access to care persist for Latino youth born in the United States (US). The association of maternal characteristics, such as maternal citizenship status and insurance coverage, on youth health insurance coverage is unclear and is important to examine given the recent sociopolitical shifts occurring in the US.

Methods: We analyzed pooled cross-sectional data from the 2010-2018 National Health Interview Survey to examine the association of Latina maternal citizenship status on maternal insurance coverage status and youth uninsurance among US-born Latino youth. Our study sample consisted of 15,912 US-born Latino youth (ages < 18) with linked mothers. Our outcome measures were maternal insurance coverage type and youth uninsurance and primary predictor was maternal citizenship status. Generalized structural equation modeling was used to examine the relationships between maternal characteristics (maternal citizenship, maternal insurance coverage status) and youth uninsurance.

Results: Overall, $7 \%$ of US-born Latino youth were uninsured. Just $6 \%$ of youth with US-born mothers were uninsured compared to almost $10 \%$ of those with noncitizen mothers. Over $18 \%$ of youth with uninsured mothers were uninsured compared to $2.2 \%$ among youth with mothers who had private insurance coverage. Compared to both US-born and naturalized citizen Latina mothers, noncitizen Latina mothers had 4.75 times the odds of reporting being uninsured. Once adjusted for predisposing, enabling, and need factors, maternal uninsurance was strongly associated with youth uninsurance and maternal citizenship was weakly associated with youth uninsurance among US-born Latino youth.

Conclusion: Maternal citizenship was associated with both maternal uninsurance and youth uninsurance among US-born Latino youth. Federal- and state-level health policymaking should apply a two-generational approach to ensure that mothers of children are offered affordable health insurance coverage, regardless of their citizenship status, thus reducing uninsurance among US-born Latino youth.
\end{abstract}

Keywords: Maternal child health, Access to health care, Health insurance, Immigration, Latinos, Disparities, Ethnicity

* Correspondence: ca529@drexel.edu

'Dornsife School of Public Health, Drexel University, 3600 Market St, Philadelphia, PA 19104, USA

Full list of author information is available at the end of the article

(c) The Author(s). 2020 Open Access This article is licensed under a Creative Commons Attribution 4.0 International License, which permits use, sharing, adaptation, distribution and reproduction in any medium or format, as long as you give appropriate credit to the original author(s) and the source, provide a link to the Creative Commons licence, and indicate if changes were made. The images or other third party material in this article are included in the article's Creative Commons licence, unless indicated otherwise in a credit line to the material. If material is not included in the article's Creative Commons licence and your intended use is not permitted by statutory regulation or exceeds the permitted use, you will need to obtain permission directly from the copyright holder. To view a copy of this licence, visit http://creativecommons.org/licenses/by/4.0/ The Creative Commons Public Domain Dedication waiver (http://creativecommons.org/publicdomain/zero/1.0/) applies to the data made available in this article, unless otherwise stated in a credit line to the data. 


\section{Background}

Latino youth in the United States (US) face persistent disparities in access to and utilization of health care services compared to their non-Latino white counterparts. These disparities may be related, in part, to parental immigration status [1, 2]. Half of all Latino youth in the US have at least one immigrant parent and approximately 4 million have at least one parent who is undocumented [3]. US-born Latino youth with immigrant parents are more likely to be uninsured and to have discontinuous health insurance coverage and are less likely to have private insurance compared to US-born Latino youth with US-born parents [4-7]. Immigrant parents are also more likely to lack awareness of and experience with health insurance, more likely to experience contextual restrictions on eligibility, and less likely to work for employers who offer health insurance [8]. Access to programs and eligibility, such as Medicaid, varies by citizenship status and can indirectly hinder access to health care services for US-born youth in immigrant families $[9,10]$.

Immigration and citizenship status have been the primary predisposing factor to understand the association between parental characteristics and youth health care access outcomes. One study found a positive association between maternal citizenship and Latino youth health insurance coverage [11], and found that even among insured immigrant parents, youth with parents who were noncitizens were more likely to be uninsured [12-14], Medicaid and Children's Health Insurance Program (CHIP) eligible youth with citizen parents were more likely to have higher participation rates compared to youth with noncitizen parents [15], Latina immigrant mothers seeking access to health services for their US-born youth may experience discrimination based on predisposing and/or enabling factors (e.g., limited English language proficiency, citizenship status) and may experience obstacles in obtaining necessary documents (e.g., proof of income) [16].

Parental enabling factors have been found to be associated with youth health insurance coverage. State-level Medicaid expansion and insuring parents with public insurance was associated with higher levels of youth public insurance coverage, retention, and continuity [17, 18]. For Latino populations in the US, sociopolitical factors have increasingly become a concern for health care access and utilization. For instance, an increase in risk of deportation is associated with a decrease in Medicaid use among mothers of youth in mixed status families [19]. Inclusive and exclusionary, federal- and state-level immigration and health policies, have implications for the health and well-being of immigrants and their youth in the US [20, 21]. For instance, Latina mothers who are not US citizens and work for employers who violate labor laws and who do not offer benefits may be more likely to be uninsured [22], which could make it more likely that their US-born Latino youth may also be uninsured and further decrease their youth's likelihoods of receiving preventive pediatric care and annual well-child visits [23]. Little is known on the association between maternal citizenship status and maternal insurance coverage status and their association with Latino youth uninsurance.

Recent anti-immigrant and anti-Latino rhetoric [24] and public charge regulation changes [25] make it timely and important to understand the pathways via which maternal characteristics, such as citizenship status and insurance coverage status, are associated with Latino youth health care access in the US. Consistent with other studies and with our aim to study the associations between predisposing, enabling, and need factors on youth health care access, we used the Andersen Behavioral Model of Health Services [26] as a framework to understand the direct and indirect pathways between maternal citizenship, maternal insurance coverage status, and youth uninsurance. We hypothesize that maternal citizenship and insurance coverage will be directly and indirectly associated with youth uninsurance among USborn Latino youth. Specifically, maternal insurance coverage status will be associated with youth uninsurance, and maternal citizenship status will be directly associated with maternal insurance coverage status and with youth insurance coverage status.

\section{Methods}

We used Stata 15 for all analyses [27] and relied on pooled 2010-2018 National Health Interview Survey (NHIS) data supplied by the Integrated Public Use Microdata Series (IPUMS) [28]. IPUMS NHIS allows for parental characteristics (e.g., maternal age, maternal educational attainment) to be linked to youth observations thus allowing for the analysis of youth linked to their mothers' characteristics. NHIS is a nationally representative, cross sectional household interview survey of the civilian, non-institutionalized population in the US. NHIS is an annual survey administered by the National Center for Health Statistics and provides information on the health of the population and covers topics such as insurance coverage, use of medical services, and health behaviors. The annual response rate of NHIS is approximately $70 \%$ of eligible households in the US [29]. Our study sample consists of US-born Latino youth less than 18 years of age with linked Latina maternal characteristics, such as foreign-born status (born in the United States or US territory, born outside of the United States), citizenship status (citizen, noncitizen), and insurance coverage status (private insurance coverage, public insurance coverage, uninsured). Latina mothers included in the sample were less than 65 years of age and who 
reported that their youngest youth was no older than 18 years old at the time of the survey $(N=15,912)$.

Our outcome measure of youth health care access was maternal reports on whether their youth had insurance coverage for the past year (uninsurance). The main predictors were maternal reports of maternal nativity and citizenship status (US-born citizen, naturalized citizen, noncitizen) and maternal insurance coverage status (private insurance coverage no/yes, public insurance coverage no/ yes, uninsured no/yes). Control variables included predisposing characteristics of maternal marital status (married, divorced/separated, never married), interview language (English/English and Spanish, Spanish/Other), maternal education level (less than high school degree, high school degree, college degree or more), maternal employment status (working, with a job but not at work), regional residence (Northeast, North Central/Midwest, South, West), and maternal age (18-29, 30-39, 40-49, and 50-64 years). Enabling factors included maternal income as a percent of the federal poverty level (FPL) (400\% and above, 200-399, 199\% and below). Need factors included maternal reports of their own general health status and of their youth's general health status (excellent or very good, good, fair or poor).

Sample descriptive statistics were performed via analysis of variance (ANOVA) tests to examine whether there were sample population mean differences in predisposing, enabling, need, and contextual variables within maternal nativity and citizenship status and maternal insurance coverage status groups. We performed a path analysis to understand the hypothesized pathways between maternal characteristics and youth uninsurance [30]. Generalized structural equation models (GSEM) were used to test the various hypotheses, where logit GSEMs were utilized due to the binary nature of our outcomes of interest. The path analysis consisted of three logit models simultaneously estimated to examine: (1) the direct association of maternal citizenship and maternal predisposing, enabling, and need characteristics on maternal insurance coverage status, (2) the association of maternal insurance coverage status on youth uninsurance, and (3) maternal characteristics, particularly maternal citizenship status, on youth uninsurance. Akaike's information criterion were included in all GSEM models to show model fit. All models were adjusted for sample weights and complex survey design for findings to represent the noninstitutionalized Latino youth population in the US, and survey year. Probit GSEM were calculated and compared with the logit model estimates to ensure the results were not due to sensitivity to model specification.

\section{Results}

Table 1 shows descriptive sample characteristics of USborn Latino youth and Latina maternal characteristics by maternal citizenship status and by maternal insurance coverage status. Almost $40 \%$ of all youth in our sample had mothers reporting that they were noncitizens, and around $34 \%$ of all youth in our sample had mothers who reported being uninsured. Overall, almost $8 \%$ of youth were uninsured with variation existing within maternal citizenship status and maternal insurance coverage status. Slightly over $6 \%$ of youth with US-born mothers were uninsured compared to almost $10 \%$ of those with noncitizen mothers. Approximately $2.2 \%$ of youth with moms who had private insurance coverage were uninsured compared to over $18 \%$ of youth with moms who were uninsured. US-born citizen mothers and mothers with private insurance coverage were more likely to report incomes above $200 \%$ FPL compared to noncitizen and uninsured mothers. Noncitizen and uninsured mothers were more likely to have less than a high school degree compared to US-born citizen and privately insured mothers.

Exponentiated logit coefficients from the GSEM analysis on the relationship between maternal characteristics, maternal insurance coverage status, and youth uninsurance are presented in Fig. 1. Noncitizen Latina mothers were less likely to report having private (OR, 0.40; 95\% CI, $0.34-0.45)$ or public health insurance coverage (OR, 0.43; 95\% CI, 0.38-0.49) compared to both US-born citizen mothers. Naturalized citizen mothers were also less likely to report having private insurance coverage compared to US-born citizen mothers (OR, 0.84; 95\% CI, 0.73-0.97). Compared to US-born citizen Latina mothers, naturalized citizen Latina mothers were more likely to report being uninsured (OR, 1.27; 95\% CI, 1.10-1.47). Noncitizen Latino mothers were more likely to report being uninsured compared to US-born Latina mothers (OR, 4.75; 95\% CI, 3.56-4.83).

After adjusting for predisposing, enabling, and need factors, we observed that Latino youth with noncitizen mothers were less likely to be uninsured compared to youth with US-born citizen mothers (OR, 0.58; 95\% CI, $0.47-0.72)$. Youth with uninsured mothers were significantly more likely to be uninsured themselves (OR, 23.2; 95\% CI, 17.2-31.1) compared to youth with mothers who had private insurance coverage.

We included an appendix containing full results from the GSEM analysis from Fig. 1 on the relationship among main predictors, control variables, and youth uninsurance (Additional file 1: Table S1) and an abbreviated table of probit GSEM analysis results on the relationship between maternal citizenship, maternal insurance coverage type, and youth insurance coverage status (Additional file 1: Table S2). The probit estimates were similar to the logit estimates.

\section{Discussion}

US-born Latino youth face persistent disparities in access to health care services compared to their non- 
Table 1 Sample characteristics among US-born Latino youth and Latina mothers by maternal foreign-born and citizenship status, and maternal insurance coverage status

\begin{tabular}{|c|c|c|c|c|c|c|c|c|c|}
\hline & \multirow[t]{2}{*}{ Total } & \multicolumn{3}{|c|}{ Maternal Citizenship Status } & & \multicolumn{3}{|c|}{ Maternal Insurance Coverage Status } & \\
\hline & & US-born Citizen & Naturalized Citizen & Noncitizen & & Private & Public & Uninsured & \\
\hline $\bar{N}$ & 15,912 & 7154 & 2517 & 6241 & $(P)$ & 6173 & 4284 & 5455 & $(P)$ \\
\hline Weighted \% & 100 & 44.9 & 15.8 & 39.2 & & 38.8 & 26.9 & 34.3 & \\
\hline \multicolumn{10}{|c|}{ Youth Uninsurance } \\
\hline No & 92.4 & 93.7 & 93.1 & 90.6 & $<0.001$ & 97.8 & 99.1 & 81.1 & $<0.001$ \\
\hline Yes & 7.6 & 6.3 & 6.9 & 9.4 & & 2.2 & 0.9 & 18.9 & \\
\hline
\end{tabular}

Predisposing Factors

Maternal Marital Status

\begin{tabular}{|c|c|c|c|c|c|c|c|c|c|}
\hline Married & 63.3 & 55.1 & 75.4 & 67.9 & $<0.001$ & 75.7 & 44.8 & 61.9 & $<0.001$ \\
\hline Divorced/Separated & 13.1 & 14.8 & 15.5 & 10.1 & & 11.3 & 17.2 & 12.4 & \\
\hline Never Married & 23.6 & 30.1 & 9.1 & 22.0 & & 13.0 & 38.0 & 25.7 & \\
\hline \multicolumn{10}{|l|}{ Interview Language } \\
\hline $\begin{array}{l}\text { English/ Spanish and } \\
\text { English }\end{array}$ & 77.5 & 95.6 & 81.0 & 55.4 & $<0.001$ & 90.4 & 76.4 & 63.5 & \multirow[t]{2}{*}{$<0.001$} \\
\hline Spanish/Other & 22.5 & 4.4 & 19.0 & 44.6 & & 9.7 & 23.6 & 36.5 & \\
\hline \multicolumn{10}{|l|}{ Maternal Education Level } \\
\hline $\begin{array}{l}\text { Less than a High School } \\
\text { Degree }\end{array}$ & 32.0 & 14.0 & 20.7 & 57.1 & $<0.001$ & 12.2 & 37.2 & 49.9 & \multirow[t]{3}{*}{$<0.001$} \\
\hline High School Degree & 53.6 & 66.5 & 57.6 & 37.2 & & 57.5 & 57.9 & 45.4 & \\
\hline College Degree or more & 14.4 & 19.5 & 21.7 & 5.8 & & 30.3 & 4.9 & 4.7 & \\
\hline \multicolumn{10}{|l|}{ Maternal Employment } \\
\hline Working/With a job & 58.1 & 66.7 & 68.9 & 43.9 & $<0.001$ & 78.3 & 45.4 & 45.7 & \multirow[t]{3}{*}{$<0.001$} \\
\hline Unemployed & 6.0 & 6.4 & 5.3 & 5.8 & & 2.1 & 9.9 & 7.7 & \\
\hline Not in Labor Force & 35.9 & 26.9 & 25.8 & 50.3 & & 19.7 & 44.7 & 46.6 & \\
\hline \multicolumn{10}{|l|}{ aternal Age } \\
\hline $18-29$ & 31.0 & 39.3 & 16.2 & 27.5 & $<0.001$ & 20.3 & 42.1 & 33.4 & \multirow[t]{4}{*}{$<0.001$} \\
\hline $30-39$ & 46.3 & 41.9 & 46.2 & 51.4 & & 49.2 & 40.1 & 48.9 & \\
\hline $40-49$ & 19.2 & 15.9 & 30.8 & 18.4 & & 25.5 & 15.0 & 15.9 & \\
\hline $50-64$ & 3.4 & 2.9 & 6.9 & 2.7 & & 4.9 & 2.9 & 1.9 & \\
\hline \multicolumn{10}{|l|}{ US Census Region } \\
\hline Northeast & 12.5 & 11.8 & 18.3 & 10.9 & 0.953 & 12.2 & 22.4 & 8.4 & \multirow[t]{4}{*}{0.462} \\
\hline North Central/Midwest & 10.0 & 10.5 & 8.1 & 10.3 & & 10.8 & 9.7 & 9.3 & \\
\hline South & 37.5 & 36.2 & 36.5 & 39.3 & & 38.3 & 20.3 & 50.2 & \\
\hline West & 40.0 & 41.5 & 37.2 & 39.5 & & 38.8 & 47.7 & 32.1 & \\
\hline \multicolumn{10}{|l|}{ abling Factor } \\
\hline \multicolumn{10}{|l|}{ Income (\%FPL) } \\
\hline $200 \%$ and above & 38.5 & 51.0 & 50.8 & 19.2 & $<0.001$ & 73.1 & 14.6 & 17.1 & \multirow[t]{3}{*}{$<0.001$} \\
\hline 100-199\% & 31.8 & 26.4 & 30.7 & 38.4 & & 21.5 & 36.0 & 39.6 & \\
\hline 99\% and below & 29.7 & 22.6 & 18.4 & 42.4 & & 5.4 & 49.4 & 43.3 & \\
\hline \multicolumn{10}{|l|}{ ed Factors } \\
\hline \multicolumn{10}{|l|}{$\begin{array}{l}\text { Maternal General } \\
\text { Health Status }\end{array}$} \\
\hline Excellent/very good & 60.7 & 62.4 & 65.8 & 56.8 & $<0.001$ & 69.2 & 52.6 & 56.9 & $<0.001$ \\
\hline Good & 30.5 & 28.3 & 27.5 & 34.3 & & 25.1 & 34.7 & 33.3 & \\
\hline
\end{tabular}


Table 1 Sample characteristics among US-born Latino youth and Latina mothers by maternal foreign-born and citizenship status, and maternal insurance coverage status (Continued)

\begin{tabular}{|c|c|c|c|c|c|c|c|c|c|}
\hline & \multirow[t]{2}{*}{ Total } & \multicolumn{3}{|c|}{ Maternal Citizenship Status } & & \multicolumn{3}{|c|}{ Maternal Insurance Coverage Status } & \\
\hline & & US-born Citizen & Naturalized Citizen & Noncitizen & & Private & Public & Uninsured & \\
\hline Fair/poor & 8.8 & 9.3 & 6.8 & 8.9 & & 5.7 & 12.7 & 9.7 & \\
\hline \multicolumn{10}{|l|}{$\begin{array}{l}\text { Youth General } \\
\text { Health Status }\end{array}$} \\
\hline Excellent/very good & 79.4 & 81.9 & 81.8 & 75.5 & $<0.001$ & 85.8 & 75.1 & 74.8 & $<0.001$ \\
\hline Good & 18.2 & 15.8 & 16.1 & 21.8 & & 13.2 & 20.9 & 22.3 & \\
\hline Fair/poor & 2.4 & 2.2 & 2.1 & 2.6 & & 1.0 & 4.1 & 2.9 & \\
\hline \multicolumn{10}{|l|}{ Contextual Characteristic } \\
\hline \multicolumn{10}{|l|}{ Year } \\
\hline 2010-2013 & 43.2 & 41.7 & 40.0 & 46.3 & $<0.001$ & 40.2 & 37.9 & 50.1 & $<0.001$ \\
\hline 2014-2015 & 22.8 & 22.3 & 23.0 & 23.4 & & 23.0 & 24.6 & 21.5 & \\
\hline 2016-2018 & 33.9 & 36.1 & 37.0 & 30.3 & & 36.7 & 37.6 & 27.9 & \\
\hline
\end{tabular}

Weighted column percentages

FPL federal poverty level

ANOVA test $(P)$ values

IPUMS National Health Interview Survey, 2010-2018

Latino white counterparts [1,2]. Given that more than half of all US-born Latino youth have at least one immigrant parent [3], and access to programs vary by citizenship status, parental characteristics may indirectly contribute to health care access disparities for youth in immigrant families $[9,10]$. Previous studies have shown an association between maternal citizenship and youth insurance coverage among Latinos [11] and that youth with noncitizen insured parents were more likely to be uninsured [12-14]. The relationship between maternal characteristics and youth health care access is limited in the literature, and to our knowledge, no other study has examined the association of maternal citizenship and insurance coverage status on health insurance coverage for US-born Latino youth. This study observed that being a noncitizen mother is directly related to maternal uninsurance and that maternal uninsurance is positively associated with youth uninsurance. Maternal citizenship status is indirectly associated with youth uninsurance for US-born Latinos. Our findings build on observations from previous studies by estimating the magnitude of the direct relationship between maternal characteristics
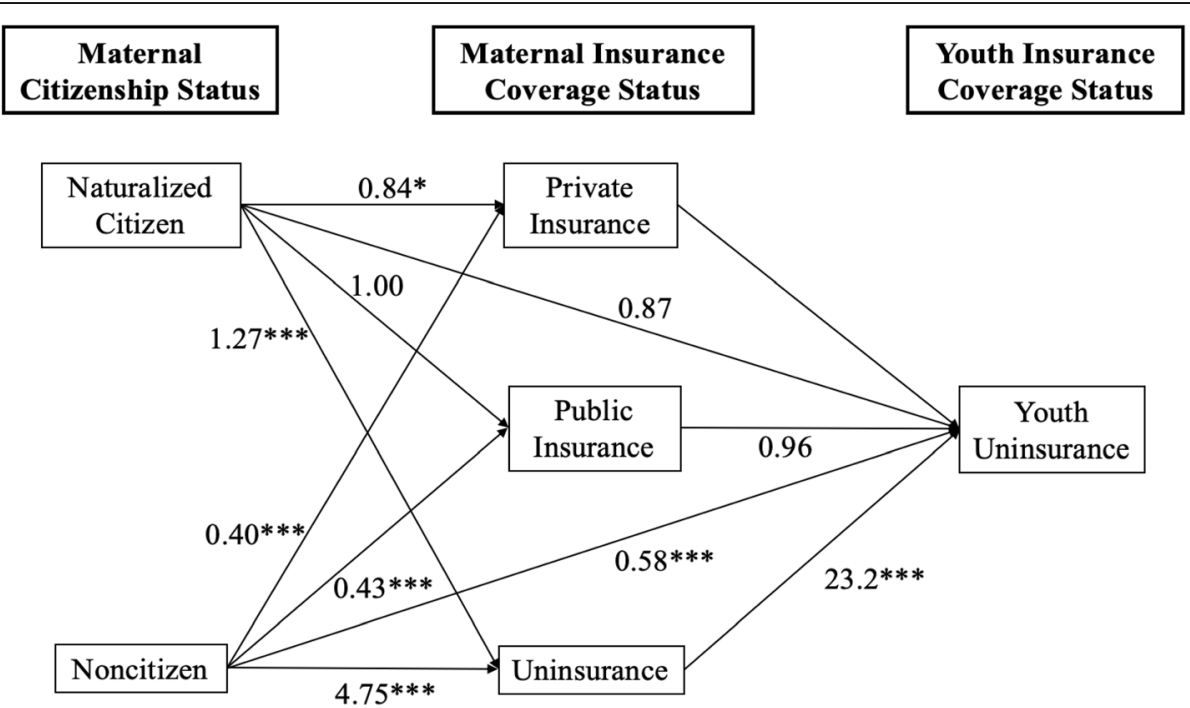

Fig. 1 Multivariate adjusted odds ratios of generalized structural equation model logit estimation of the association among maternal citizenship, maternal insurance coverage status and youth uninsurance. Reference groups are youth with US-born citizen mothers and youth with mothers who have private insurance coverage. Estimates are adjusted for maternal marital status, interview language, maternal educational level, maternal employment, maternal age, region, income, maternal general health status, and youth general health status. ${ }^{*} P<0.05$. ${ }^{* * *} P<0.001$ 
and youth uninsurance. Elucidating these relationships is important given the present and ongoing anti-immigrant and Latino rhetoric [24] and public charge regulation changes [25] that may increase health care access disparities for US-born Latino youth in immigrant families.

Noncitizen Latina mothers are more likely to be uninsured compared to US-born and naturalized citizen mothers in our study which is consistent with previous reports that found over $20 \%$ of lawfully present immigrants and more than $40 \%$ of undocumented immigrants are uninsured compared to less than $8 \%$ of US citizens [22]. These disparities could be related with citizenship status-based restrictions on eligibility for public insurance, and/or a greater likelihood of noncitizens working for employers who do not offer health insurance and/or who violate labor and wage laws, leading to lower incomes that limit the ability to afford paying premiums for private insurance or employer sponsored insurance [22]. Contextual characteristics are also associated with insurance coverage disparities for Latina immigrant mothers. For example, an increase in risk of deportation was associated with a decrease in Medicaid use among Latina mothers in mixed status families [19]. Lastly, the passage of exclusionary federal- and state-level immigration and health policies, such as the current administration's changes to public charge policy [25] or undocumented immigrants being excluded from the Patient Protection and Affordable Care Act (ACA), influence health care access and the overall health of immigrants and of their US-born youth $[20,21]$.

We found that youth with noncitizen mothers were less likely to be uninsured compared to youth with USborn and naturalized citizen mothers. This is contrary to a previous finding that youth with Medicaid and CHIP eligible parents were more likely to be insured compared to youth with noncitizen parents [15]. This finding is a weak association compared to the association between maternal uninsurance and youth uninsurance and thus should be interpreted with caution. Maternal uninsurance is significantly associated with youth uninsurance and maternal citizenship is associated with maternal uninsurance, indicating that there is a strong indirect pathway between maternal citizenship and youth uninsurance. While maternal citizenship was indirectly related to youth uninsurance, we found that youth with noncitizen mothers were less likely to be uninsured but, importantly, that maternal uninsurance was related to youth uninsurance and noncitizen mothers had much higher odds of being uninsured than their citizen counterparts, which is important given that US-born Latino youth make up the largest racial and ethnic group among all youth in the US [31] and many of them are members of immigrant families. This indirect pathway in the relationship between maternal citizenship and youth uninsurance, as we observed, may operate through maternal uninsurance-given that citizenship is used to determine eligibility for full-time employment and health insurance coverage options (e.g., health insurance marketplaces from the ACA [22]), noncitizen mothers are more likely to be uninsured compared to citizen mothers. Maternal citizenship is associated with maternal insurance coverage status, which is then associated with youth uninsurance among US-born Latino youth.

Our findings may vary by region or state in the US. We found that US-born Latino youth who reside in the Southern region of the US had the highest odds of being uninsured nationally, which is consistent with policy restrictions on public benefits for immigrants compared to the Northeast [32]. Latina immigrant mothers may also be more likely to experience discrimination when attempting to access care for their youth based on their own characteristics, such as their English language proficiency and citizenship status [16], which may be more common in the South [33]. If immigrant Latina mothers continue to be excluded from health care access by restrictive federal and state policies [34], then the disparities in health care outcomes among US-born Latino youth could widen.

Having access to health insurance coverage is a significant factor in utilizing services, especially the preventive care and annual well-child visits for youth suggested by the American Academy of Pediatrics [35]. In this study, while we examined health insurance coverage status for youth and their mothers, it is important to discuss that maternal citizenship and its association with insurance is indicative of systemic discrimination based on documentation and citizenship status [10]. Health policies that are enacted in the US and at the state-level can either be inclusive or exclusionary [10] in nature and in this study, we observed that being a noncitizen was strongly associated with being uninsured. This demonstrates that US health policy is excluding noncitizens explicitly from accessing affordable health insurance coverage options.

Our findings should be interpreted within several limitations. First, we cannot determine the relationships between several different variations of citizenship and documentation status (e.g., legal permanent resident, undocumented) and that may lead to underestimating the relationship between maternal citizenship and maternal uninsurance, and youth uninsurance. For instance, if in our noncitizen category, legal permanent residents are overrepresented, we may be underestimating the relationship between maternal citizenship status and maternal insurance for moms who may be undocumented and their youth's uninsurance. Youth uninsurance may be far greater among youth with mothers who are undocumented and uninsured, and we are unable to capture this level of detail in our citizenship measure. Second, 
we rely on a repeated cross-sectional design survey and we cannot control whether maternal characteristics change over time per observation even with the use of fixed effects for survey year. For instance, if a mother is a noncitizen and becomes a citizen and we cannot examine how this change would influence their own and their youth's uninsurance. Third, while we control for region of residence, we were unable to include state level indicators which would be more informative given that state level policies have larger health implications for immigrant populations. Lastly, while our use of generalized structural equation modeling has been novel in our understanding of the pathways between maternal characteristics and youth uninsurance for US-born Latino youth, we cannot fully confirm the direction of causality within the relationships we sought to understand because the data are cross-sectional.

\section{Conclusion}

Maternal characteristics are associated with youth uninsurance among US-born Latino youth. Specifically, maternal citizenship is a pathway to youth uninsurance through maternal insurance coverage status suggesting that ensuring health care access for Latino youth in the US may depend on whether mothers have adequate access to health care. States can improve access to health care by utilizing a two-generational approach to health policy and expand Medicaid and CHIP to all children regardless of their own and family's immigration status, thus further reducing youth uninsurance for youth in immigrant families.

\section{Supplementary information}

Supplementary information accompanies this paper at https://doi.org/10. 1186/s12889-020-09188-1.

Additional file 1: Table S1. Odds ratios from generalized structural equation model logit estimation of Latina maternal characteristics, Latina maternal insurance coverage status, and youth uninsurance. Table S2. Odds ratios from generalized structural equation model probit estimation of Latina maternal citizenship status, Latina maternal insurance coverage status, and youth uninsurance.

\section{Abbreviations}

US: United States of America; CHIP: Children's Health Insurance Program; NHIS: National Health Interview Survey; IPUMS: Integrated Public Use Microdata Series; FPL: Federal Poverty Level; ANOVA: Analysis of Variance; GSEM: Generalized Structural Equation Modeling; OR: Odds ratio (i.e. exponentiated logit coefficient); ACA: Patient Protection and Affordable Care Act

\section{Acknowledgements}

Not applicable.

\section{Authors' contributions}

CKA led study inception and design, conducted the analysis and interpretation, and led the writing of the manuscript. JKP, BL, LPT, APMD interpreted the results and contributed substantially to revisions of the analysis and writing. JPS contributed to the design of the study, analysis, and interpretation of results and contributed substantially to revisions of the manuscript. All authors approved and agree to be personally accountable for the final manuscript.

\section{Funding}

The authors declare that they did not receive any funding for this study.

\section{Availability of data and materials}

The dataset that was analyzed during the study are available for download for free from the Integrated Public Use Microdata Series National Health Interview Survey website (https://nhis.ipums.org/nhis/).

\section{Ethics approval and consent to participate}

Our study relied on a secondary dataset that does not contain identifiable information of survey participants. The dataset is publicly available for research use and no approval was required from any institutional review board. No administrative permissions and/or licenses were required or acquired by coauthors to access the data used in this study.

\section{Consent for publication}

Not applicable.

\section{Competing interests}

The authors declare that they have no competing interests.

\section{Author details}

${ }^{1}$ Dornsife School of Public Health, Drexel University, 3600 Market St, Philadelphia, PA 19104, USA. ²Department of Health Management and Policy, Dornsife School of Public Health, Drexel University, 3215 Market St, Nesbitt Hall, Philadelphia, PA 19104, USA. ${ }^{3}$ Department of Epidemiology and Biostatistics, Dornsife School of Public Health, Drexel University, 3215 Market St, Nesbitt Hall, Philadelphia, PA 19104, USA. ${ }^{4}$ Department of Community Health and Prevention, Dornsife School of Public Health, Drexel University, 3215 Market St, Nesbitt Hall, Philadelphia, PA 19104, USA

Received: 26 March 2020 Accepted: 1 July 2020

Published online: 11 July 2020

\section{References}

1. Langellier BA, Chen J, Vargas-Bustamante A, Inkelas M, Ortega AN. Understanding health-care access and utilization disparities among Latino children in the United States. J Child Health Care. 2016;20(2):133-44.

2. Avila RM, Bramlett MD. Language and immigrant status effects on disparities in Hispanic Children's health status and access to health care. Matern Child Health J. 2013;17(3):415-23.

3. Clarke W, Turner K, Guzman L. In: Scarupa HA-G, A, editor. One quarter of Hispanic children in the United States have an unauthorized immigrant parent. Bethesda: National Research Center on Hispanic Children \& Families; 2017. http://www.hispanicresearchcenter.org/wp-content/uploads/2018/04/ Hispanic-Center-Undocumented-Brief-FINAL-V2.pdf.

4. DeCamp LR, Bundy DG. Generational status, health insurance, and public benefit participation among low-income Latino children. Matern Child Health J. 2012;16(3):735-43.

5. Weathers AC, Novak SP, Sastry N, Norton EC. Parental nativity affects children's health and access to care. J Immigr Minor Health. 2008;10(2): 155-65.

6. Hamilton ER, Hummer RA, You XH, Padilla YC. Health insurance and healthcare utilization of U.S.-born Mexican-American children*. Soc Sci Q. 2006; 87(5):1280-94

7. Weathers AC, Novak SP, Sastry N, Norton EC. Parental nativity is an important factor associated with where children usually go for health care. Matern Child Health J. 2008;12(4):499-508.

8. BeLue R, Miranda PY, Elewonibi BR, Hillemeier MM. The association of generation status and health insurance among U.S. children. Pediatrics. 2014;134(2):307-14.

9. Torres JM, Young MD. A life-course perspective on legal status stratification and health. SSM Popul Health. 2016:2:141-8.

10. De Trinidad Young M-E, León-Pérez G, Wells CR, Wallace SP. More inclusive states, less poverty among immigrants? An examination of poverty, citizenship stratification, and state immigrant policies. Popul Res Policy Rev. 2018;37(2):205-28.

11. Hernandez DC, Kimbro RT. The association between acculturation and health insurance coverage for immigrant children from socioeconomically disadvantaged regions of origin. J Immigr Minor Health. 2013;15(3):453-61. 
12. Guendelman S, Angulo V, Wier M, Oman D. Overcoming the odds: access to care for immigrant children in working poor families in California. Matern Child Health J. 2005;9(4):351-62.

13. Huang ZI, Yu SM, Ledsky R. Health status and health service access and use among children in U.S. immigrant families. Am J Public Health. 2006;96(4):634-40.

14. Acevedo-Garcia D, Stone LC. State variation in health insurance coverage for U.S. citizen children of immigrants. Health Aff. 2008;27(2):434-46.

15. Kenney GM, Lynch V, Cook A, Phong S. Who and where are the children yet to enroll in Medicaid and the children's health insurance program? Health Aff. 2010;29(10):1920-9.

16. Perreira KM, Crosnoe R, Fortuny K, Pedroza J, Ulvestad K, Weiland C, Yoshikawa H, Chaudry A. In: Services OotASfPaEUDoHaH, editor. https:// aspe.hhs.gov/basic-report/barriers-immigrants-access-health-and-humanservices-programs Barriers to immigrants access to health and human services programs; 2012

17. Yamauchi M, Carlson MJ, Wright BJ, Angier H, DeVoe JE. Does health insurance continuity among low-income adults impact their children's insurance coverage? Matern Child Health J. 2013;17(2):248-55.

18. DeVoe JE, Marino M, Angier H, O'Malley JP, Crawford C, Nelson C, Tillotson CJ, Bailey SR, Gallia C, Gold R. Effect of expanding medicaid for parents on children's health insurance coverage: lessons from the Oregon experiment. JAMA Pediatr. 2015;169(1):e143145.

19. Vargas ED. Immigration enforcement and mixed-status families: the effects of risk of deportation on Medicaid use. Child Youth Serv Rev. 2015;57:83-9.

20. Perreira KM, Pedroza JM. Policies of exclusion: implications for the health of immigrants and their children. Annu Rev Public Health. 2019;40:147-66.

21. Stimpson JP, Wilson FA. Medicaid expansion improved health insurance coverage for immigrants, but disparities persist. Health Affairs. 2018;37(10): 1656-62.

22. Health Coverage of Immigrants [https://www.kff.org/disparities-policy/factsheet/health-coverage-of-immigrants/]. Accessed 10 Jan 2020.

23. Venkataramani M, Pollack CE, Roberts ET. Spillover effects of adult medicaid expansions on children's use of preventive services. Pediatrics. 2017;140(6): e20170953; https://doi.org/10.1542/peds.2017-0953.

24. Newhauser D, McMorris-Santoro E. Hispanic leaders say trump's antiimmigrant language is fueling violence like el paso. In: VICE News. Brooklyn: VICE; 2019. https://www.vice.com/en_us/article/xweqan/hispanic-leaderssay-trumps-anti-immigrant-language-is-fueling-violence-like-el-paso.

25. Changes to "Public Charge" Inadmissibility Rule: Implications for Health and Health Coverage [https://www.kff.org/disparities-policy/fact-sheet/publiccharge-policies-for-immigrants-implications-for-health-coverage/]. Accessed 10 Jan 2020.

26. Andersen RM. National health surveys and the behavioral model of health services use. Med Care. 2008;46(7):647-53.

27. Stata Statistical Software: Release 15 [https://www.stata.com/support/faqs/ resources/citing-software-documentation-faqs/]. Accessed 10 Jan 2020.

28. Blewett LA, Rivera Drew JA, Griffin R, King ML, Williams KCW. IPUMS health surveys: National Health Interview Survey. Minneapolis: IPUMS; 2019

29. About the National Health Interview Survey [https://www.cdc.gov/nchs/ nhis/about_nhis.htm]. Accessed 10 Jan 2020.

30. Kenny DA. Reflections on mediation. Organ Res Methods. 2008;11(2):353-8.

31. Racial and Ethnic Composition of the Child Population. [https://www. childtrends.org/indicators/racial-and-ethnic-composition-of-the-childpopulation]. Accessed 10 Jan 2020.

32. Health and Health Coverage in the South: A Data Update [https://www.kff. org/disparities-policy/issue-brief/health-and-health-coverage-in-the-south-adata-update/]. Accessed 10 Jan 2020.

33. Why Hispanics Are Leaving Some Southern Counties [https://www. pewtrusts.org/en/research-and-analysis/blogs/stateline/2017/08/02/whyhispanics-are-leaving-some-southern-counties]. Accessed 10 Jan 2020.

34. Health Coverage and Care of Undocumented Immigrants [https://www.kff. org/disparities-policy/issue-brief/health-coverage-and-care-ofundocumented-immigrants/]. Accessed 10 Jan 2020

35. Hagan JF, Shaw JS, Duncan PM. Bright futures: guidelines for health supervision of infants, Chidlren, and adolescents; periodicity schedule. 4th ed. Elk Grove Village: American Academy of Pediatrics; 2017. https://www. aap.org/en-us/Documents/periodicity_schedule.pdf.

\section{Publisher's Note}

Springer Nature remains neutral with regard to jurisdictional claims in published maps and institutional affiliations.

Ready to submit your research? Choose BMC and benefit from:

- fast, convenient online submission

- thorough peer review by experienced researchers in your field

- rapid publication on acceptance

- support for research data, including large and complex data types

- gold Open Access which fosters wider collaboration and increased citations

- maximum visibility for your research: over $100 \mathrm{M}$ website views per year

At BMC, research is always in progress.

Learn more biomedcentral.com/submissions 